\title{
Efeito do chorume líquido de suínos na podridão do colo e tombamento de plântulas de feijoeiro causadas por Sclerotium rolfsii
}

\author{
Rafael G.F. Morales, Idalmir dos Santos \& Moeses A. Danner \\ Coordenação de Agronomia, Universidade Tecnológica Federal do Paraná, Campus Pato Branco, \\ Cx. Postal 571, CEP 85501-970, Pato Branco, PR, Brasil, e-mail: idalmir@utfpr.edu.br
}

Autor para correspondência: Idalmir dos Santos

MORALES, R.G.F., SANTOS, I. \& DANNER, M.A. Efeito do chorume líquido de suínos na podridão do colo e tombamento de plântulas de feijoeiro causadas por Sclerotium rolfsii. Fitopatologia Brasileira 32:429-433. 2007.

\begin{abstract}
RESUMO
O chorume líquido de suínos (CLS) pode ser utilizado como fonte de nutrientes e de matéria orgânica para algumas culturas agrícolas e interferir na ocorrência de doenças de plantas, causadas por fitopatógenos habitantes do solo. Assim, foi estudado o efeito do CLS, sobre as doenças do feijoeiro (Phaseolus vulgaris) causadas por Sclerotium rolfsii. Em parcelas de $1 \mathrm{~m}^{2}$, foi incorporado o CLS nas doses equivalentes a $0,20,40,60$ e $80 \mathrm{~m}^{3} \mathrm{ha}^{-1}$. O solo foi infestado dois meses antes da aplicação do CLS, com $100 \mathrm{~g}$ do substrato (arroz em casca) colonizado pelo patógeno. A semeadura de 80 sementes de feijão por parcela foi efetuada em dois cultivos sucessivos, 1 dia e 45 dias após a aplicação do CLS. A intensidade da doença foi avaliada através da emergência, estande final de plântulas e severidade da doença, nos dois cultivos, sendo que a atividade microbiana, a concentração de amônia na camada superficial do solo e os níveis de fertilidade foram avaliados apenas no segundo cultivo. Com o aumento das doses de CLS foi verificada a redução da intensidade da doença e, entre as características avaliadas, o aumento da atividade microbiana, da concentração de amônia e dos níveis de cobre e zinco são os que melhor explicam essa redução.
\end{abstract}

Palavras-chave adicionais: Matéria orgânica, atividade microbiana, solo supressivo.

\begin{abstract}
Effect of liquid swine manure on collar rot and damping-off of bean plantlets caused by Sclerotium rolfsii

Liquid swine manure (LSM) can be used as a source of nutrients and organic matter for some agricultural crops, and may interfere in plant diseases caused by soil-borne plant pathogens. Thus, the effect of LSM on bean (Phaseolus vulgaris) diseases caused by Sclerotium rolfsii was studied. LSM was incorporated into $1 \mathrm{~m}^{2}$ plots at doses equivalent to 0 , $20,40,60$, and $80 \mathrm{~m}^{3} \mathrm{ha}^{-1}$. The soil was infested two months prior to LSM application with $100 \mathrm{~g}$ of substrate (unhulled rice) colonized by the pathogen. Eighty bean seeds were sown per plot in two successive cultivations, 1 day and 45 days after LSM application. Intensity of the disease was evaluated based on plant emergence, final stand, and severity of the disease, in both cultivations. Microbial activity, ammonia concentration at the soil surface layer, and fertility levels were only evaluated in the second cultivation. A reduction in disease intensity was observed as LSM doses increased. Among the characteristics evaluated, the factors that best explain such a reduction are increased microbial activity, ammonia concentration, and copper and zinc levels.
\end{abstract}

Additional keywords: Organic matter, microbial activity, suppressive soil.

O fungo Sclerotium rolfsii Sacc. é um fitopatógeno altamente agressivo e de difícil controle. Estratégias como tratamento químico ou biológico das sementes, resistência genética e rotação de culturas, auxiliam na redução de seu inóculo, mas apresentam baixa eficiência. Outra alternativa para o controle é a incorporação de compostos orgânicos ao solo, os quais melhoram as suas características físicas, químicas e microbiológicas.

Os compostos orgânicos podem atuar nos fitopatógenos diretamente pela produção de compostos químicos ou indiretamente favorecendo o aumento da população dos antagonistas (Hoitink \& Fahy, 1986). O uso de compostos orgânicos, na maioria dos casos, apresenta efeitos supressivos na redução da severidade das doenças e na redução da população de patógenos do solo (Santos \& Bettiol, 2003; Blum \& Rodríguez-Kábana, 2004, 2006), pois a matéria orgânica ativa a microbiota, provoca alterações no $\mathrm{pH}$ e na condutividade elétrica do solo, fatores que podem estimular a supressividade do solo aos fitopatógenos. Segundo Santos \& Bettiol (2003), a adição de lodo de esgoto ao solo, controlou a podridão do colo e o tombamento do feijoeiro, induzidos por $S$. rolfsii, reduzindo a severidade das doenças.

Além dos fatores citados, a quantidade e a forma dos nutrientes contidos nos compostos orgânicos podem interferir no efeito sobre as doenças de plantas (Dissanayake \& Hoy, 1999). A supressão da podridão de esclerotínia na alface, obtida com lodo de esgoto compostado, foi associada com o aumento dos níveis de $\mathrm{N}, \mathrm{P}, \mathrm{Ca}$ e $\mathrm{Mg}$ no solo, como, também, ao aumento da atividade microbiana (Lumsden et al., 1986).

O chorume líquido de suínos (CLS) é utilizado na 
agricultura como fonte de nutrientes e matéria orgânica. No entanto, a sua utilização para controle de doenças de plantas é pouco estudada. Solos submetidos à criação de suínos ao ar livre foram supressivos ao tombamento de plântulas de pepino causado por Pythium aphanidermatum (Edson) Fitzp. (Tirelli et al., 2003). Lazarovits (2001) constatou que com uma única aplicação de CLS $\left(57 \mathrm{~m}^{3}\right.$ ha $\left.\mathrm{a}^{-1}\right)$, houve redução por três anos consecutivos de murcha da batata causada por Verticillium dahliae Kleb. Segundo o autor, a adição de CLS ao solo aumentou as populações microbianas e alterou as espécies de microrganismos predominantes, sendo que os níveis elevados do agente de controle biológico Trichoderma, foram evidentes em muitos dos solos tratados com CLS. Em trabalhos posteriores, Tenuta \& Lazarovits (2002) e Conn et al. (2005) observaram que a concentração de CLS utilizada, a composição química do CLS e as características de solo, principalmente o $\mathrm{pH}$, influenciaram na liberação de compostos químicos no solo, como a amônia, ácidos graxos voláteis e ácido nitroso, os quais tiveram efeito tóxico aos microescleródios de $V$. dahliae.

O efeito da aplicação do CLS ao solo, principalmente na microbiota e doenças de plantas, ainda está carente de resultados e sobre as doenças causadas por $S$. rolfsii, não foi encontrado nenhum estudo. Sendo assim, o presente trabalho teve como objetivo avaliar o efeito do CLS sobre as doenças causadas por S. rolfsii em feijoeiro (Phaseolus vulgaris L.) e seu possível modo de ação. O trabalho foi realizado a campo na Universidade Tecnológica Federal do Paraná (UTFPR), Campus Pato Branco, Brasil, latitude $26^{\circ} 11^{\prime} 50^{\prime \prime}$ S, longitude $52^{\circ} 41^{\prime} 26^{\prime \prime} \mathrm{W}$ e altitude de $816 \mathrm{~m}$, num latossolo vermelho distrófico.

O efeito do CLS sobre S. rolfsii foi avaliado em parcelas de $1 \mathrm{~m}^{2}$, nas quais o solo havia sido infestado em 05/01/2004, dois meses antes da aplicação do CLS, com $100 \mathrm{~g}$ por parcela do substrato contendo o patógeno. Para tanto, um isolado de $S$. rolfsii foi multiplicado em meio de cultura esterilizado contendo $100 \mathrm{~g}$ de arroz em casca e $150 \mathrm{~mL}$ de água destilada, contidos em frascos de um litro, durante 10 dias, à temperatura de $25^{\circ} \mathrm{C} \pm 2$, com fotoperíodo de 12 horas. Anteriormente à instalação do ensaio foram realizados dois cultivos de feijão para verificar a presença e a homogeneidade de ocorrência da doença nas parcelas, as quais foram confirmadas.

O delineamento experimental foi de blocos casualizados, com quatro repetições (parcelas de $1 \mathrm{~m}^{2}$ ) e cinco tratamentos, com doses de CLS equivalentes a 0,20 , 40, 60 e $80 \mathrm{~m}^{3} \mathrm{ha}^{-1}$, com uma única aplicação em 10/03/2004. O CLS foi coletado na estação experimental do Instituto Agronômico do Paraná (IAPAR), localizada no município de Pato Branco, Paraná, contendo os seguintes atributos físicos e químicos, obtidos em base seca: densidade $1,60 \mathrm{~g}$ $\mathrm{cm}^{-3} ; \mathrm{pH}$ em água 7,4; N, P, K, Ca e Mg, 31,50; 21,78; 97,00; 28,48 e 9,20 $\mathrm{g} \mathrm{kg}^{-1}$, respectivamente; $\mathrm{Cu}, \mathrm{Zn}, \mathrm{Mn}, \mathrm{B}, \mathrm{Cr}, \mathrm{Co}$, $\mathrm{Ni}, \mathrm{Pb}$ e Cd, 2489,9; 1387,6; 375,37; 166,63; 104,48; 14,04; 21,07; 28,66 e 5,20 mg kg${ }^{-1}$, respectivamente.

Foram realizados dois cultivos sucessivos de feijão, com a semeadura de 80 sementes por parcela, em 11/03/2004 e em 26/04/2004, 1 dia e 45 dias após a aplicação do CLS, respectivamente. A cultivar utilizada foi a UTF-1, a qual apresentava $94 \%$ de poder germinativo. Durante o primeiro cultivo, de 11/03 a 03/04/2004, a temperatura mínima diária variou de 12,8 a $19,4^{\circ} \mathrm{C}$, a temperatura máxima de 23,2 a $32,6^{\circ} \mathrm{C}$, a temperatura média de 18,7 a $23,3^{\circ} \mathrm{C}$, a umidade relativa do ar de $45,2 \%$ a $92 \%$ e a precipitação pluviométrica total foi de $50 \mathrm{~mm}$. No segundo cultivo, 26/04 a 19/05/2004, a temperatura mínima diária variou de 4,6 a $15,6^{\circ} \mathrm{C}$, a temperatura máxima de 14 a $26,6^{\circ} \mathrm{C}$, a temperatura média de 9,6 a $18,8^{\circ} \mathrm{C}$, a umidade relativa do ar de $65,2 \%$ a $98,9 \%$ e a precipitação pluviométrica total foi de $148 \mathrm{~mm}$. Ocorreu precipitação pluviométrica em apenas três e seis dias, no primeiro e segundo cultivo, respectivamente. Por isso, foi efetuada a irrigação das parcelas até capacidade de campo, nos dias em que não ocorreu precipitação. As condições climáticas foram mensuradas na estação meteorológica do IAPAR, Pato Branco PR.

A intensidade da doença, referente aos dois cultivos, foi avaliada considerando-se a emergência de plantas, o estande final e a severidade. A atividade microbiana, a concentração de amônia $\left(\mathrm{NH}_{3}\right)$ na camada superficial do solo e os níveis de fertilidade foram avaliados apenas no segundo cultivo. A metodologia utilizada para as avaliações de emergência e estande final foi realizada contandose o número de plântulas emergidas após 12 dias da semeadura e o total de plântulas remanescentes após 24 dias. A severidade da doença foi avaliada, aos 24 dias da semeadura, considerando a porcentagem de tecido lesionado no colo da plântula, com base na escala diagramática para podridões radiculares do feijoeiro (Schoonhoven \& PastorCorrales, 1987). Antes das avaliações da severidade foi feita a identificação e a confirmação da doença causada por $S$. rolfsii, tendo em vista que as estruturas do fungo foram visualizadas nos tecidos das sementes que não germinaram e das plântulas que não emergiram do solo ou tombaram após a emergência. O patógeno foi isolado dos tecidos do colo das plântulas submetidas à avaliação da severidade e identificado visualmente.

Para a avaliação do desprendimento de $\mathrm{CO}_{2}$ foram coletadas amostras, em seis pontos de cada parcela, as quais foram homogeneizadas e peneiradas $(4 \mathrm{~mm})$. Em seguida, $100 \mathrm{~g}$ de solo por parcela foram incubados em recipientes hermeticamente fechados, com volume de 2 litros, contendo no interior uma tampa de uma placa de Petri invertida onde foram adicionados $10 \mathrm{ml}$ de $\mathrm{KOH}(0,5 \mathrm{~N})$, os quais foram colocados em ambiente escuro, a temperatura $25^{\circ} \mathrm{C} \pm 2$. Dois outros recipientes, contendo apenas $10 \mathrm{~mL}$ de $\mathrm{KOH}(0,5 \mathrm{~N})$ nas placas de Petri, foram mantidos como controle. Após 15 dias de incubação, o KOH foi titulado com $\mathrm{HCl}(0,1 \mathrm{~N})$.

Para as análises de $\mathrm{pH}$, fertilidade e concentração de amônia foram retiradas quatro amostras de solo, em cada unidade experimental, na profundidade de $0-10 \mathrm{~cm}$, utilizando-se um trado tipo holandês. As amostras foram homogeneizadas e encaminhadas ao laboratório de solos 
da UTFPR, Campus Pato Branco. Os dados obtidos foram submetidos à análise de variância, análise de regressão e teste de correlação de Pearson a 5\% de probabilidade de erro.

Com as doses crescentes de CLS verificou-se redução da intensidade da doença, e entre os fatores relacionados diretamente destacou-se a emergência de plântulas. No primeiro cultivo, a média de emergência foi de $34,1 \%$ no tratamento testemunha, havendo um incremento de $4,1 \%$ na menor dose e de $37,1 \%$ na maior dose $\left(r^{2}=0,96\right)$ (Tabela 1$)$. No segundo cultivo, a média de emergência foi de $40,8 \%$ para a testemunha, com um incremento de $8,2 \%$ na menor dose e $34,1 \%$ na maior dose de CLS $\left(r^{2}=0,91\right)$ (Tabela 1$)$.

Outro fator que evidenciou o efeito positivo do CLS na proteção do feijoeiro contra o patógeno foi o estande final de plântulas. O número de plântulas apresentou um aumento expressivo conforme o aumento das doses de CLS nos dois cultivos $\left(\mathrm{r}^{2}=0,94 ; \mathrm{r}^{2}=0,87\right.$; respectivamente) (Tabela 1). No primeiro cultivo, onde a média de plântulas na testemunha foi de $28,6 \%$, o incremento do número de plântulas foi de $13,5 \%$ na menor dose de CLS e $51 \%$ na maior dose. No segundo cultivo, a média do número de plântulas na testemunha foi de $32,5 \%$ e o incremento do número de plântulas foi de $6,3 \%$ e $64,6 \%$, para a menor e a maior dose de CLS, respectivamente.

O efeito do CLS, avaliado pela severidade da doença, apresentou resultados expressivos nos dois cultivos. No primeiro cultivo, a severidade foi de $60,5 \%$ na testemunha, sendo reduzida para $43,2 \%$ na maior dose $\left(r^{2}=0,98\right)$. A severidade da doença no segundo cultivo foi de $56 \%$ na testemunha e $41,1 \%$ na maior dose de CLS $\left(r^{2}=0,89\right)$ (Tabela 1).

Os níveis de matéria orgânica na camada superficial do solo $(0-10 \mathrm{~cm})$ foram de $50,3 \mathrm{~g} \mathrm{dm}^{-3}$ para as doses de 0,20 e $40 \mathrm{~m}^{3} \mathrm{ha}^{-1}$ de CLS, aumentando para 55,3 e 59,6 $\mathrm{g} \mathrm{dm}^{-3}$ nas doses de 60 e $80 \mathrm{~m}^{3} \mathrm{ha}^{-1}$ de CLS $\left(\mathrm{r}^{2}=0,78\right)$, respectivamente. Os resultados indicaram que o coeficiente de correlação entre o aumento dos níveis de matéria orgânica com o aumento da atividade microbiana, avaliada por meio do desprendimento de $\mathrm{CO}_{2}$, foi de $90 \%$ e, possivelmente, influenciou a relação patógeno-hospedeiro, resultando na supressão da doença.

$\mathrm{O}$ aumento da atividade microbiana, induzido pelas doses crescentes de CLS, parece ser o principal fator relacionado com a redução das doenças. $\mathrm{O}$ aumento do desprendimento de $\mathrm{CO}_{2}$ explicou em $95 \%$ o aumento da emergência e do estande final de plântulas e em 93\% a redução da severidade da doença, pela análise de correlação. Dissanayake \& Hoy (1999) concluíram que o aumento da atividade microbiana, provocada pela aplicação de matéria orgânica ao solo, e a própria microbiota contida no material orgânico, foram os responsáveis pelo controle de doenças em pepino e cana-de-açúcar causadas por Pythium ultimum Trow e $P$. aphanidermatum, respectivamente. A atividade microbiana do solo é aumentada durante a decomposição da matéria orgânica e se traduz em ação antagônica entre os microrganismos, com mecanismos de ação de antibiose, competição e parasitismo (Millner et al., 1982).

Além da liberação de $\mathrm{CO}_{2}$ indicar uma maior atividade microbiana, ela pode, por si só, inibir a germinação do patógeno. $\mathrm{O}$ desprendimento de $\mathrm{CO}_{2}$ aumentou de 12,2 mg para 18,0 mg em $100 \mathrm{~g}$ de solo seco $\left(\mathrm{r}^{2}=0,96\right)$ (Tabela 1). Segundo Griffin \& Nair (1968), a taxa de crescimento micelial e germinação de escleródios de $S$. rolfsii foram reduzidos por concentrações crescentes de $\mathrm{CO}_{2}$, o qual é produto do crescimento microbiano e atua como mecanismo de antagonismo.

As doses crescentes de CLS não alteraram o $\mathrm{pH}$ de forma expressiva, não sendo possível relacioná-lo como um fator isolado que tenha atuado sobre o fitopatógeno ou na manifestação das doenças (Tabela 1). No entanto, as principais reações que ocorrem no solo estão em função

TABELA 1 - Efeito do chorume líquido de suínos sobre a emergência de plantas, o estande final e a severidade da doença em plantas de feijoeiro (cultivar UTF-1) causada por Sclerotium rolfsii no $1^{\circ}$ e $2^{\circ}$ cultivos e o $\mathrm{pH}$, a atividade microbiana (liberação de $\mathrm{CO}_{2}$ ) e a concentração de amônia no solo no $2^{\circ}$ cultivo após a incorporação do chorume

\begin{tabular}{|c|c|c|c|c|c|c|c|c|c|c|c|c|c|}
\hline & \multicolumn{13}{|c|}{ Dose de chorume líquido de suínos $\left(\mathrm{m}^{3} \mathrm{ha}^{-1}\right)$} \\
\hline & \multicolumn{8}{|c|}{$1^{\circ}$ cultivo } & \multicolumn{5}{|c|}{$2^{\circ}$ cultivo } \\
\hline & $\mathbf{0}$ & 20 & 40 & 60 & 80 & $\mathbf{r}^{2}$ & C.V. & $\mathbf{0}$ & 20 & 40 & 60 & 80 & $\mathbf{r}^{2}$ \\
\hline Emergência (\%) & $34,1^{*}$ & 35,4 & 41,3 & 43,5 & 46,7 & 0,96 & 9,1 & 40,8 & 44,1 & 52,1 & 54 & 54,8 & 0,91 \\
\hline Incremento na emergência (\%) & - & 4,1 & 21,4 & 27,8 & 37,1 & - & - & - & 8,2 & 27,5 & 32,6 & 34,1 & - \\
\hline Estande final $(\%)$ & 28,6 & 32,5 & 38,4 & 40,7 & 43,2 & 0,94 & 12,4 & 32,5 & 34,6 & 48,9 & 53,4 & 53,5 & 0,87 \\
\hline Incremento no estande final (\%) & - & 13,5 & 34 & 42,3 & 51 & - & - & - & 6,3 & 50,2 & 64,3 & 64,6 & - \\
\hline Severidade da doença $(\%)$ & 60,5 & 56,2 & 50,1 & 48 & 43,2 & 0,98 & 8,4 & 56 & 49,2 & 47,6 & 39,7 & 41,1 & 0,89 \\
\hline $\mathrm{pH}$ & 5,7 & 5,5 & 5,8 & 5,5 & 5,6 & NS & 0,6 & 5,6 & 5,6 & 5,8 & 5,6 & 5,6 & NS \\
\hline $\mathrm{CO}_{2}\left(\mathrm{mg} 100 \mathrm{~g}^{-1}\right.$ de solo seco $)$ & NM & $\mathrm{NM}$ & NM & NM & NM & NM & NM & 12,2 & 13,2 & 15 & 16,5 & 18 & 0,96 \\
\hline Amônia ( $\mathrm{mg} \mathrm{kg}^{-1}$ de solo) & NM & NM & NM & NM & NM & NM & NM & 32,1 & 33,1 & 36,3 & 43,7 & 45,6 & 0,99 \\
\hline
\end{tabular}

*Média de quatro parcelas; NM: não mensurado; NS: não significativo a 5\% de probabilidade de erro pelo teste $\mathrm{F}$. 
do seu pH. Para Lazarovits (2001), é o pH que determina o controle de $V$. dahliae na presença de CLS, visto que em $\mathrm{pH}$ abaixo de 6 os ácidos graxos voláteis são, provavelmente, responsáveis pelo controle do fitopatógeno, enquanto que em pH alcalino, acima de 8, aumenta a liberação da amônia, a qual é tóxica ao fitopatógeno. Em trabalhos posteriores, Tenuta et al. (2002) e Conn et al. (2005) observaram que a concentração e a composição química do CLS e as características de solo, principalmente o $\mathrm{pH}$, influenciaram na liberação de compostos químicos no solo, como a amônia, ácidos graxos voláteis e ácido nitroso, os quais tiveram efeito tóxico aos microescleródios de $V$. dahliae. Conn et al. (2005) ratificam as informações da maior toxicidade da amônia em $\mathrm{pH}$ alcalino e dos ácidos voláteis em $\mathrm{pH}$ ácido e acrescentam o efeito tóxico do ácido nitroso em $\mathrm{pH}$ ácido. No presente trabalho, o $\mathrm{pH}$ do solo variou entre 5,5 e 5,8. Portanto, é possível que os ácidos graxos voláteis e o ácido nitroso tenham afetado o fitopatógeno $S$. rolfsii, reduzindo a intensidade das doenças causadas em feijoeiro.

Mesmo em se tratando de um solo ácido, o aumento da concentração de amônia na camada superficial do solo foi relacionado com a redução da doença. Sua concentração aumentou de $32,1 \mathrm{mg} \mathrm{kg}^{-1}$ de solo na testemunha, para 45,6 $\mathrm{mg} \mathrm{kg}{ }^{-1}$ de solo na maior dose de CLS $\left(\mathrm{r}^{2}=0,99\right)$ (Tabela 1). O aumento da concentração da amônia explicou em $89 \%$ o aumento da emergência, em $91 \%$ o aumento do estande e em $93 \%$ a redução da severidade da doença. Quando os microrganismos degradam compostos com alto teor de nitrogênio, como é o caso do CLS, o excedente pode ser liberado na solução do solo como amônia $\left(\mathrm{NH}_{3}\right)$, que em concentrações altas pode ser tóxica à $V$. dahliae (Lazarovits, 2001). O fato da amônia ter atuado na redução da doença em solo com $\mathrm{pH}$ ácido, pode ser explicado devido as altas doses de CLS utilizadas, o tipo de solo, o mecanismo de ação e a estrutura do fitopatógeno atingida. Segundo Tenuta \& Lazarovits (2002), a adição de rejeitos de carne e ossos, a 2,5\%, a um solo areno-argiloso ácido resultou no acúmulo de amônia e na morte de microescleródios de $V$. dahliae.

Conn et al. (2005) afirmam que as características do CLS (conteúdo de ácidos graxos voláteis e amônia, e capacidade tamponante de $\mathrm{pH}$ ) determinam o seu potencial para a formação de compostos letais no solo, e que as propriedades físicas, químicas $(\mathrm{pH}$, conteúdo de matéria orgânica e capacidade tamponante) e biológicas (degradação dos ácidos graxos voláteis e taxa de nitrificação) e temperatura e umidade do solo, determinam a formação e concentração finais dos compostos letais.

A combinação de características físicas, químicas e biológicas do latossolo vermelho distrófico, associada à composição e concentração do CLS utilizado neste trabalho, pode ter favorecido o acúmulo de amônia em concentração suficiente para reduzir a ação do $S$. rolfsii sobre o feijoeiro. Tenuta et al. (2002) afirmam que a amônia é capaz de penetrar rapidamente nas membranas das células sendo tóxica aos microrganismos. No presente trabalho é possível que a amônia tenha reduzido a ação do $S$. rolfsii penetrando nas estruturas vegetativas do mesmo, em concentrações menores que as exigidas para matar os microescleródios de V. dahliae.

Com relação aos nutrientes avaliados no solo, apenas os incrementos nas concentrações de $\mathrm{Zn}$ e $\mathrm{Cu}$ podem ser relacionados ao potencial do CLS em suprimir as doenças induzidas por $S$. rolfsii em feijoeiro. As doses crescentes de $\operatorname{CLS}\left(0,20,40,60\right.$ e $\left.80 \mathrm{~m}^{3} \mathrm{ha}^{-1}\right)$ induziram um aumento nas concentrações de zinco $(7,0 ; 10,9 ; 16,1 ; 20,6$; e 24,0 mg dm ${ }^{3}$ de solo) $\left(\mathrm{r}^{2}=0,99\right)$, respectivamente; e de cobre $(4,7 ; 4,8$; 4,$8 ; 5,0 ;$ e $4,9 \mathrm{mg} \mathrm{dm}^{-3}$ de solo) $\left(\mathrm{r}^{2}=0,79\right)$, respectivamente. O coeficiente de correlação entre o aumento da concentração desses dois íons metálicos com o aumento da emergência, do estande final e a redução da severidade da doença foram $96 \%, 96 \%$ e $95 \%$ para zinco, e $89 \%, 89 \%$ e $98 \%$ para cobre, respectivamente. Segundo Zambolim \& Ventura (1993), o zinco pode aumentar o conteúdo de ácido ascórbico e carboidratos das plantas, conferindo dessa forma a resistência no algodoeiro à murcha de Fusarium oxysporum f.sp. vasinfectum W.C. Snyder \& H.N. Hansen. Segundo os autores, o íon cobre pode induzir resistência às doenças pelo aumento da síntese de peróxidos, compostos fenólicos e quinonas. Entretanto, é importante monitorar os teores desses elementos no solo, pois apesar de serem micronutrientes, são metais pesados que facilmente podem contaminar o solo se as aplicações forem contínuas nas áreas.

No presente trabalho, verificou-se que há influência de vários fatores na indução de supressividade do solo à $S$. rolfsii após aplicação do CLS, como a liberação de $\mathrm{CO}_{2}$, $\mathrm{NH}_{3}, \mathrm{Zn}$ e $\mathrm{Cu}$ e a atividade microbiana, demonstrando a complexidade envolvendo a relação composto orgânico, solo, planta e fitopatógeno neste tipo de estudo.

Salienta-se que, mesmo na maior dose de CLS onde se obteve a maior proteção do feijoeiro contra o fitopatógeno, o número de plântulas emergidas foi menor que o número de sementes. Foram semeadas 80 sementes por parcela e a maior média de plântulas obtidas foi de 53,58 na maior dose de CLS no segundo cultivo. Este fato pode ser explicado pelo alto potencial de inóculo do patógeno, que foi colocado no solo neste experimento, situação não encontrada em condições normais de cultivo de campo. Isso indica que os resultados obtidos com a aplicação do CLS no solo para a proteção do feijoeiro contra $S$. rolfsii são promissores.

\section{REFERÊNCIAS BIBLIOGRÁFICAS}

BLUM, L.E.B. \& RODRÍGUEZ-KÁBANA, R. Effect of soil organic amendments on sclerotial germination, mycelial growth, and Sclerotium rolfsii-induced diseases. Fitopatologia Brasileira 29:66-74. 2004.

BLUM, L.E.B. \& RODRÍGUEZ-KÁBANA, R. Powders of kudzu, velvetbean and pine bark added to soil increase microbial population and reduce southern blight of soybean. Fitopatologia Brasileira 31:551-556. 2006. 
CONN, K. L., TENUTA, M. \& LAZAROVITS, G. Liquid swine manure can kill Verticillium dahliae microsclerotia in soil by volatile fatty acid, nitrous acid, and ammonia toxicity. Phytopathology 95:28-35. 2005.

DISSANAYAKE, N. \& HOY, J.W. Organic material soil amendment effects on root rot and sugarcane growth and characterization of the materials. Plant Disease 83:1039-1046. 1999.

GRIFFIN, D.M. \& NAIR, N.G. Growth of Sclerotium rolfsii at different concentration of oxygen and carbon dioxide. Journal of Experimental Botany 19:812-816. 1968.

HOITINK, H.A.J. \& FAHY, P.C. Basis for the control of soilborne plant pathogens with composts. Annual Review of Phytopathology 24:93-114. 1986.

LAZAROVITS, G. Management of soil-borne plant pathogens with organic soil amendments: a disease control strategy salvaged from the past. Canadian Journal Plant Pathology 23:1-7. 2001.

LUMSDEN, R.D., MILLNER, P.D. \& LEWIS, J.A. Suppression of lettuce drop caused by Sclerotinia minor with composted sewage sludge. Plant Disease 70:197-201. 1986.

MILLNER, P.D., LUMSDEN, R.D. \& LEWIS, J.A. Controlling plant disease with sludge compost. Biocycle 23:50-52. 1982.

SANTOS, I. \& BETTIOL, W. Effect of sewage sludge on the rot and seedling damping-off of bean plants caused by Sclerotium rolfsii. Crop Protection 22:1093-1097. 2003.

SCHOONHOVEN, A. van \& PASTOR-CORRALES, M.A. Standard System for the Evaluation of Bean Germplasm. Cali. CIAT. 1987.

TENUTA, M. \& LAZAROVITS, G. Ammonia and nitrous acid from nitrogenous amendments kill the microesclerotia of Verticillium dahliae. Phytopathology 92:255-264. 2002.

TENUTA, M., CONN, K.L., \& LAZAROVITS, G. Volatile fatty acids in liquid swine manure can kill microsclerotia of Verticillium dahliae. Phytopathology 92:548-552. 2002.

TIRELLI, L.A., SANGALETTI, E. \& SANTOS, I. Efeito de solo submetido à criação de suínos ao ar livre sobre as doenças do pepino causadas por Pythium aphanidermatum. Anais, Evento Científico SAEPE/JICC, Pato Branco. 2003. pp.189-192.

ZAMBOLIM, L. \& VENTURA, J.A. Resistência a doenças induzida pela nutrição mineral das plantas. Revisão Anual de Patologia de Plantas 4:275-318. 1993.

Recebido 5 Outubro 2006 - Aceito 25 Setembro 2007 - FB 6100 